\title{
Thyrotoxicosis formation due to functioning metastatic follicular thyroid cancer
}

Sadiye Altun Tuzcu ${ }^{1 *}$, Faruk Kılınç², Zafer Pekkolay ${ }^{3}$, Hikmet Soylu ${ }^{3}$, Alpaslan Kemal Tuzcu $^{3}$

\begin{abstract}
Thyrotoxicosis is a common condition, which is associated with excess circulating thyroid hormones. Rarely, thyrotoxicosis may develop due to metastatic thyroid carcinoma. Most of patients with functional thyroid cancer metastases have normal thyroxine (T4) concentrations with high serum triiodothyronine (T3thyrotoxicosis). Inappropriately supressed Thyroid Stimulating Hormone (TSH) level with normal T4 level may be an indicator of T3 thyrotoxicosis. In this article, a thyrotoxicosis case, due to metastatic follicular thyroid cancer with a huge metastatic lesion was represented.
\end{abstract}

Keywords: Adenocarcinoma, Follicular, Thyrotoxicosis

\section{Introduction}

Thyrotoxicosis is a common condition associated with excess circulating thyroid hormones. It is important to identify the cause of the thyrotoxicosis to determine treatment approaches. Graves' disease, toxic multinodular goitre, thyroid nodule, thyroiditis, drugs (such as amiodarone, lithium, interferon $\alpha$ ), $\beta$ human chorionic gonadotrophin mediated hyperthyroidism (gestational hyperthyroidism, choriocarcinoma, hydatidiform mole) Struma ovary, non-autoimmune familial hyperthyroidism and Thyroid Stimulating Hormone (TSH) secreting pituitary adenoma are the important causes of thyrotoxicosis (1). Rarely, thyrotoxicosis may develop due to functioning of metastatic thyroid carcinoma $(2,3)$. In this case report we present a recognised case of thyrotoxicosis due to metastatic follicular thyroid cancer with a huge metastatic lesion.

\section{Case Report}

A 59-year-old female patient was admitted to our clinic with a painful, progressively enlarging mass around her right shoulder. The patient had elevated serum free triiodothyronine (free T3) normal serum free thyroxine (free T4) and low thyroid-stimulating hormone (TSH) Blood hormone levels of patient were shown in Table 1. The patient had thyroidectomy history 10 years ago due to multinodular goitre. She had not informed about her thyroid pathology. She had noticed a growing mass on the right shoulder for few years.
Three years ago, biopsy of the mass had been performed and pathological examination revealed the thyroid follicular cancer. The patient had not taken any medication. Moreover, the physical examination revealed that the patient has a right scapular mass. In addition, patient also has diabetes and getting intensive insulin therapy. Complete blood count was normal. The patient's elevated alkaline phosphatase and residual thyroid tissue $(19 \times 11 \mathrm{~mm})$ could be observed at the right side of the neck by ultrasonographic examination. The whole body was scanned using radioiodine imaging with I-131. The results showed an increased uptake in right scapular infero-lateral region (Figure 1). The MRI scan of the right shoulder showed a huge mass $(150 \mathrm{X} 111 \mathrm{~mm})$, which includes bone and soft tissue (Figure-2a/2b). We planned metastatic mass excision, followed by the radioiodine ablation treatment, but the patient did not accept our therapy recommendations.

Table 1: Laboratory characteristics of the patient

\begin{tabular}{lcc} 
& $\begin{array}{c}\text { Normal } \\
\text { range }\end{array}$ & $\begin{array}{c}\text { Patient's } \\
\text { result }\end{array}$ \\
\hline TSH (uIU/ml) & $0.270-4.2$ & 0,01 \\
Free T4 (ng/dL) & $12-22$ & 3.91 \\
Free T3 (ng/dL) & $3,9-6,7$ & 18,57 \\
Tiroglobulin (ng/mL) & $1,4-78$ & 500 \\
Alkaline phosphatase (U/L) & $40-150$ & 259 \\
Glucose (mg/dL) & $70-109$ & 196 \\
\hline
\end{tabular}

Received 29-09-2016 Accepted 11-10-2016 Available Online 15-10-2016

1 Gazi Yasargil Education and Research Hospital, Dept of Nuclear Medicine, Yenisehir, Diyarbakır, Turkey,

2 Elazıg Education and Research Hospital Dept of Endocrinology, Elazıg, Turkey,

3 Dicle University Faculty of Medicine Dept of Endocrinology Diyarbakır, Turkey

* Corresponding Author: Sadiye Altun Tuzcu E-mail: sadiyetuzcu@yahoo.com.tr Phone: +90 4122580060 


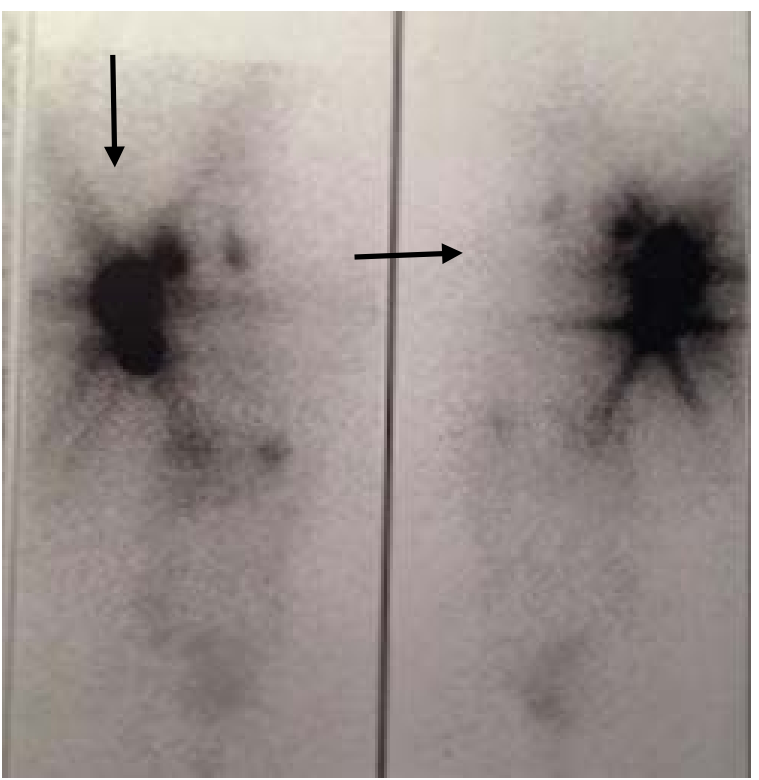

Figure 1: Whole body radioiodine imaging with I-131 showed increased uptake in the right scapular region

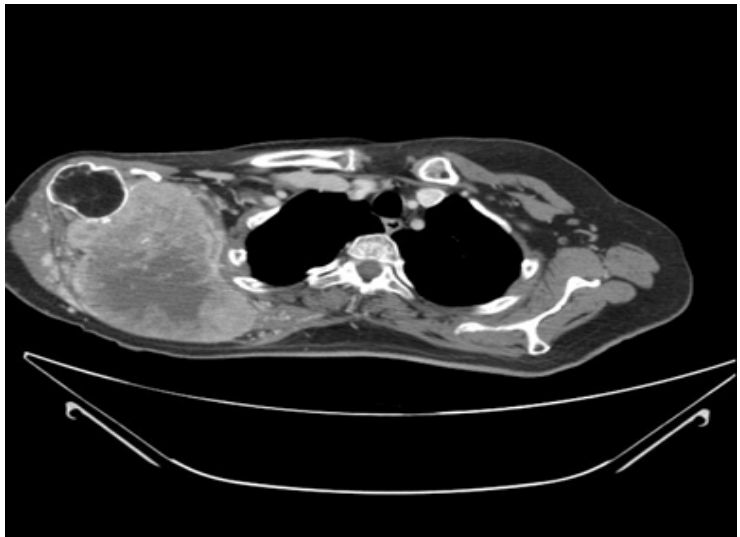

Figure 2a Magnetic Resonance Imagining (MRI) of the patient's right shoulder (Upward-Over)

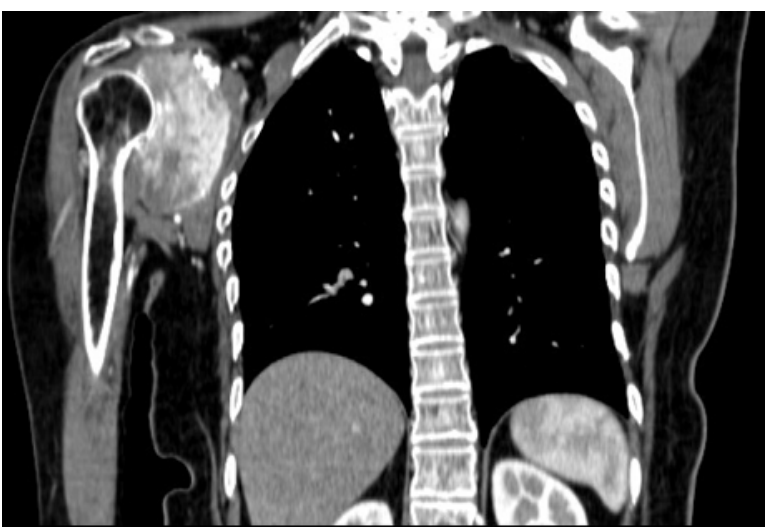

Figure 2b Magnetic Resonance Imagining (MRI) of the patient's right shoulder (Front)

\section{Discussion}

The formation of thyrotoxicosis due to functional thyroid cancer metastases is extremely rare, and is mostly caused by follicular cancer. Even so, hyper functioning papillary thyroid cancer has been documented $(3,4)$. The patient had follicular cancer of the thyroid gland.

The functional metastases had been identified using whole body radioiodine imaging. of the patient with I131. The results have shown an increased uptake in right scapular region. Previously, she was not informed or aware about her pathology specimen and was not treated with high dose radioactive iodine for thyroid cancer ablation. Small metastasis of follicular cancer of the thyroid may be asymptomatic, but bulky and extensive metastasis of cancer may lead to thyrotoxicosis.

The majority of patients with functional thyroid cancer metastases have had high serum triiodothyronine (T3) but normal thyroxine (T4) concentrations (T3-thyrotoxicosis). Patients who have thyrotoxicosis due to functioning metastatic thyroid carcinoma have predominantly T3 thyrotoxicosis (2).

Our patient's serum thyroglobulin and free T3 were elevated. She had normal free $t 4$ and supressed TSH level. Thyroid cancer patients especially follow up with thyroglobulin, free 44 and TSH levels but, in our opinion at least once a year, measuring free $\mathrm{t} 3$ may be helpful and give an opportunity to diagnose T3 thyrotoxicosis cases.

In patients who take TSH-suppressive thyroid hormone therapy with L-thyroxine after total thyroidectomy, the presence of hyper functioning metastases may not be readily occur. Gradual reduction or withdrawal of L-thyroxine therapy is necessary in order to recognize whether the thyrotoxicosis is caused by excessive exogenous levothyroxine or hyper functioning metastases. The mechanism is high activity of the type 1 and type 2 iodothyronine deiodinases in tumour tissues, ie. exogenously administered levothyroxine is converted to T3 (5).

A few of these patients have also had serum TSHreceptor stimulating antibodies, the presence of which would be expected to increase the hormonal synthetic capacity of the cancer (6). We did not measure TSH receptor stimulating antibodies level due to technical failure.

\section{Conclusion}

In conclusion, 1- Follicular thyroid cancer can cause hyper functioning metastatic huge mass lesions. 2Inappropriately supressed TSH levels with normal T4 levels may be helpful to suspect T3 thyrotoxicosis. 
Conflict of Interest: The authors declare no potential conflicts of interest with respect to the research, authorship, and/or publication of this article.

Acknowledgement: Author Contributions: A.K.T.: Concept, S.A.T.: Design, Z.P.: Data collection and processing, F.K.: Literature search, H.S.: Writing

\section{References}

1. Vaidya B, Pearce SH. Diagnosis and management of thyrotoxicosis. BMJ. 2014 Aug 21;349:g5128.

2. Nakashima $\mathrm{T}$, Inoue $\mathrm{K}$, Shiro-ozu A, Yoshinari $\mathrm{M}$, Okamura K, Itoh M. Predominant T 3 synthesis in the metastatic thyroid carcinoma in a patient with $\mathrm{T}$ 3toxicosis. Metabolism. 1981 Apr 30;30(4):327-30.

3. Paul SJ, Sisson JC. Thyrotoxicosis caused by thyroid cancer. Endocrinology and metabolism clinics of North America. 1990 Sep;19(3):593-612.

4. Russo D, Tumino S, Arturi F, Vigneri P, Grasso G, Pontecorvi A, Filetti S, Belfiore A. Detection of an Activating Mutation of the Thyrotropin Receptor in a Case of an Autonomously Hyperfunctioning Thyroid Insular Carcinoma 1. The Journal of Clinical Endocrinology \& Metabolism. 1997 Mar 1;82(3):735-8.

Ethical issues: All Authors declare that Originality of research/article etc... and ethical approval of research, and responsibilities of research against local ethics commission are under the Authors responsibilities. The study was conducted due to defined rules by the Local Ethics Commission guidelines and audits. Miyauchi A, Takamura Y, Ito Y, Miya A, Kobayashi K,
Matsuzuka F, Amino N, Toyoda N, Nomura E, Nishikawa M. 3, 5, 3' -Triiodothyronine thyrotoxicosis due to increased conversion of administered levothyroxine in patients with massive metastatic follicular thyroid carcinoma. The Journal of Clinical Endocrinology \& Metabolism. 2008 Jun;93(6):2239-42.

6

Kasagi K, Takeuchi R, Miyamoto S, et al. Rapid Control of T3 Thyrotoxicosis in Patients with Metastatic Follicular Thyroid Cancer Treated Metastatic thyroid cancer presenting as thyrotoxicosis: report of three cases. Clin Endocrinol (Oxf) 1994; 40:429. 